\title{
Moringa oleifera leaf extracts protect BMSC osteogenic induction following peroxidative damage by activating the $\mathrm{PI} 3 \mathrm{~K} / \mathrm{Akt} /$ Foxo1 pathway
}

Meiling Liu, Haifeng Ding, Hongzhi Wang, Manfeng Wang, Xiaowei Wu*, Lu Gan*, Luyang Cheng and Xianglu Li

\begin{abstract}
Objective: We aimed to investigate the therapeutic effects of Moringa oleifera leaf extracts on osteogenic induction of rat bone marrow mesenchymal stem cells (BMSCs) following peroxidative damage and to explore the underlying mechanisms.

Methods: Conditioned medium was used to induce osteogenic differentiation of BMSCs, which were treated with $\mathrm{H}_{2} \mathrm{O}_{2}$, Moringa oleifera leaf extracts-containing serum, or the phosphatidyl inositol-3 kinase (PI3K) inhibitor wortmannin, alone or in combination. Cell viability was measured using the MTT assay. Cell cycle was assayed using flow cytometry. Expression levels of Akt, phosphorylated (p)Akt, Foxo 1, and cleaved caspase-3 were analyzed using western blot analysis. The mRNA levels of osteogenesis-associated genes, including alkaline phosphatase (ALP), collagen I, osteopontin (OPN), and Runx2, were detected using qRT-PCR. Reactive oxygen species (ROS) and malondialdehyde (MDA) levels, as well as superoxide dismutase (SOD), glutathione peroxidase (GSH-PX), and ALP activity were detected using commercially available kits. Osteogenic differentiation capability was determined using alizarin red staining.
\end{abstract}

Results: During osteogenic induction of rat $\mathrm{BMSCs}, \mathrm{H}_{2} \mathrm{O}_{2}$ reduced cell viability and proliferation, inhibited osteogenesis, increased ROS and MDA levels, and decreased SOD and GSH-PX activity. $\mathrm{H}_{2} \mathrm{O}_{2}$ significantly reduced pAkt and Foxo1 expression, and increased cleaved caspase-3 levels in BMSCs. Additional treatments with Moringa oleifera leaf extracts partially reversed the $\mathrm{H}_{2} \mathrm{O}_{2}$-induced changes. Wortmannin partially attenuated the effects of Moringa oleifera leaf extracts on protein expression of Foxo1, pAkt, and cleaved caspase-3, as well as mRNA levels of osteogenesis-associated genes.

Conclusion: Moringa oleifera leaf extracts ameliorate peroxidative damage and enhance osteogenic induction of rat BMSCs by activating the PI3K/Akt/Foxo1 pathway.

Keywords: Moringa oleifera leaf extracts, Bone marrow mesenchymal stem cells, Osteogenic induction, Hydrogen peroxide, PI3K/Akt pathway, Foxo1

\footnotetext{
* Correspondence: wuxiaowei@hrbmu.edu.cn; ganlu@hrbmu.edu.cn Department of Geriatrics, Second Affiliated Hospital of Harbin Medical University, 246 Xuefu Road, Nangang District, Harbin 150086, China
}

(c) The Author(s). 2021 Open Access This article is licensed under a Creative Commons Attribution 4.0 International License, which permits use, sharing, adaptation, distribution and reproduction in any medium or format, as long as you give appropriate credit to the original author(s) and the source, provide a link to the Creative Commons licence, and indicate if changes were made. The images or other third party material in this article are included in the article's Creative Commons licence, unless indicated otherwise in a credit line to the material. If material is not included in the article's Creative Commons licence and your intended use is not permitted by statutory regulation or exceeds the permitted use, you will need to obtain permission directly from the copyright holder. To view a copy of this licence, visit http://creativecommons.org/licenses/by/4.0/ The Creative Commons Public Domain Dedication waiver (http://creativecommons.org/publicdomain/zero/1.0/) applies to the data made available in this article, unless otherwise stated in a credit line to the data. 


\section{Introduction}

Aging can cause peroxidative damage, which can lead to decreased bone mass and osteoporosis [1], which is closely related to frailty [2], increasing the risk of negative events such as disability, paralysis, and tumble [3]. Osteoporosis is a disease caused by multiple pathogenic factors $[4,5]$, and severe osteoporosis represents a disease of high mortality and morbidity [6]. Individuals with a high probability of osteoporotic fractures present a very significant disease burden to society, and this burden is set to increase markedly in the future [7]. At present, clinical treatment for osteoporosis is carried out from a single path, but with little efficacy and adverse reactions.

Bone marrow mesenchymal stem cells (BMSCs) are a subgroup of cells with multi-differentiation potential, and their directed differentiation is a complex process involving multiple cellular pathways. BMSCs are defined by their phenotypic expression of CD44, CD90, and CD105, and absence of expression of hematopoietic markers such as CD45, CD34, and CD14 [8]. BMSCs with multi-differentiation properties are currently used to treat a variety of diseases, such as type 1 diabetes, inflammatory bowel disease, and cardiac disease [9-11]. Several studies have demonstrated that BMSCs can be induced to differentiate into bone cells under specific induction conditions $[12,13]$. Recently, infusion of BMSCs has been considered a promising strategy to treat osteoporosis. For example, studies in animal models have revealed that both allogeneic and autologous BMSC transplantation is applicable in the treatment of osteoporosis [14]. Accumulating evidence has confirmed that transplantation of BMSCs can promote formation of new bones, improve bone quality, and prevent osteoporosis-associated bone fractures [15-17].

Moringa oleifera is an angiosperm plant, and various parts of the plant have been utilized throughout history as food and medicine [18]. In recent years, it has been found that Moringa oleifera has good anti-oxidative, hypoglycemic, hypolipidemic, anti-tumor, and antifungal activities [19-24]. Studies have confirmed that the Moringa flower extract has the highest antioxidant capacity, followed by the Moringa leaf extract [25]. Remarkably, Moringa oleifera leaves have a positive preventive and therapeutic effect on various chronic diseases [26]. Studies have also shown that the high nutrient content and various biological activities of Moringa oleifera can improve the oxidative state of postmenopausal women [27], but there is no relevant report on its effects on ameliorating osteoporosis.

In this study, we established an in vitro peroxidative damage model of primary rat BMSCs using $\mathrm{H}_{2} \mathrm{O}_{2}$. Moringa oleifera leaf extracts containing serum were used to test the protective effects on BMSCs challenged with peroxidative damage during osteogenic differentiation, and we explored the possible cellular and molecular mechanisms underlying the protective properties of Moringa oleifera by using wortmannin (an inhibitor of phosphoinositide-3 kinase) [28].

\section{Materials and methods \\ BMSC cell culture}

Primary cultures of rat BMSCs were prepared from eight Sprague-Dawley rats aged 3 to 4 weeks weighing $100 \pm$ $10 \mathrm{~g}$. Male rats maintained in specific-pathogen-free (SPF) conditions were provided by the Animal Experimental Center of the Second Affiliated Hospital of Harbin Medical University, Harbin, China. For the experiments involving in vitro osteogenic differentiation of BMSCs, rats were obtained from the Animal Experimental Center and sacrificed by cervical dislocation after being euthanized with $\mathrm{CO}_{2}$ inhalation. This study was approved by the Institutional Animal Care and Use Committee of Harbin Medical University.

After $\mathrm{CO}_{2}$ euthanasia, rats were sacrificed by cervical dislocation and soaked in $75 \%$ ethanol for $10 \mathrm{~min}$. The bilateral femur and tibia of rats were removed under aseptic conditions. The periosteum and muscle tissue were dissected, and the femur and tibia were washed with phosphate buffered saline (PBS) three times. Next, the medullary cavity was cut and washed repeatedly with DMEM/F12 medium (Hyclone; Logan City, UT, USA) containing 10\% fetal bovine serum (Biological Industries; Beit Haemek, Israel). After centrifugation at $1200 \mathrm{rpm}$ for $5 \mathrm{~min}$, the bone marrow cells in the pellets were inoculated into cell culture flasks with complete DMEM/ F12 medium and cultured in a humidified atmosphere with $5 \% \mathrm{CO}_{2}$ at $37{ }^{\circ} \mathrm{C}$. The culture medium was changed for the first time in $48 \sim 72 \mathrm{~h}$, and then changed every $2 \sim 3$ days. When reaching $80 \%$ confluence, the adherent cells were passaged after trypsin digestion, and third generation BMSCs (P3 cells) at the logarithmic growth phase were used for subsequent experiments.

To induce commitment toward an osteogenic lineage, P3 cells were cultured in osteogenic differentiation induction (OS) medium, which was comprised of DMEM/ F12 culture medium supplemented with fetal bovine serum (10\%), $50 \mu \mathrm{g} / \mathrm{ml}$ vitamin $\mathrm{C}, 10 \mathrm{mmol} / \mathrm{L} \quad \beta$ glycerophosphate, and $0.1 \mu \mathrm{mol} / \mathrm{L}$ dexamethasone (Solarbio; Beijing, China), as previously reported [29].

\section{Immunofluorescence analysis of BMSCs}

BMSCs at the third passage were fixed with $4 \%$ paraformaldehyde for $15 \mathrm{~min}$ and blocked with $5 \%$ bovine serum albumin (BSA) in TBST (Tris-buffered saline, $0.1 \%$ Tween 20 ). Cells were probed with primary antibodies (1:100 dilution) against CD44, CD90, CD31, and CD34 (Absin, Shanghai, China) overnight at $4{ }^{\circ} \mathrm{C}$. Bound 
antibodies were detected with Cy3-conjugated goat antirabbit IgG (1:400 dilution; Absin, Shanghai, China) and FITC-conjugated goat anti-mouse IgG (1:100 dilution, Zhongsu Jinqiao, Beijing, China), followed by a nuclear staining with 4',6-diamidino-2-phenylindole (DAPI). Cells stained with secondary antibody only were considered negative controls. Fluorescent signals were detected using a fluorescence microscope (Nikon Eclipse Ti, Nikon, Japan).

\section{Cell treatment and grouping}

The P3 cells cultured in OS medium were treated with $\mathrm{H}_{2} \mathrm{O}_{2}(50 \mu \mathrm{mol} / \mathrm{L}$ to $200 \mu \mathrm{mol} / \mathrm{L})$ or $0.5 \mu \mathrm{mol} / \mathrm{L}$ wortmannin (phosphatidyl inositol-3 kinase (PI3K) inhibitor; Solarbio; Beijing, China), as indicated in each experimental design. $\mathrm{H}_{2} \mathrm{O}_{2}(100 \mu \mathrm{mol} / \mathrm{L})$ was selected to test the impacts of Moringa leaf-containing serum (10\%). The P3 cells were divided into the following groups: Table 1

$\mathrm{H}_{2} \mathrm{O}_{2}$ treatment lasted $24 \mathrm{~h}$ starting at $0 \mathrm{~h}$, and the cells in the $\mathrm{MO}+\mathrm{H}_{2} \mathrm{O}_{2}+$ Wor group were treated with $0.5 \mu \mathrm{mol} / \mathrm{L}$ wortmannin for $24 \mathrm{~h}$ starting from $0 \mathrm{~h}$. The OS medium or the medium supplemented with $10 \%$ Moringa leaf extract-containing serum was changed every 3 days. Cell cycle, oxidative stress, and protein expression were all assayed at $48 \mathrm{~h}$ after initiation of osteogenic differentiation. After 7 days of induction, the expression levels of genes for osteogenic markers were determined. ALP staining was examined on day 14, and osteogenesis determination was examined on day 21 after osteogenic differentiation.

\section{Preparation and analysis of drug-containing serum}

Moringa leaf micropowder was provided by Heilongjiang Academy of Sciences (Harbin, China). Moringa leaf solution was made by dissolving the micropowder in saline and mixing well. Male rats weighing $250 \pm 20 \mathrm{~g}$ were administered Moringa leaf solution through oral dosing $(0.5 \mathrm{~g} / \mathrm{kg} /$ day $)$ at the frequency of twice per day for three consecutive days. Rats in the control group were given normal saline. Fifteen rats were used in preparation of drug-containing serum. At $1 \mathrm{~h}$ after the last dosing, blood was extracted from the heart after the euthanasia. Blood was collected and centrifuged at $300 \mathrm{rpm}$ for 20 $\mathrm{min}$ at room temperature. The serum was sterilized by suction filtration and stored at $-20{ }^{\circ} \mathrm{C}$. This study was approved by the Institutional Animal Care and Use Committee of Harbin Medical University.

The drug-containing serum was analyzed using Nontarget High Performance Liquid Chromatography (HPLC). LC-MS/MS analyses were performed using an UHPLC system (1290, Agilent Technologies; Santa Clara, CA, USA) with a UPLC HSS T3 column $(2.1 \mathrm{~mm}$ $\times 100 \mathrm{~mm}, 1.8 \mu \mathrm{m}$ ) coupled to Q Exactive (Orbitrap MS,
Thermo Fisher Scientific; Waltham, MA, USA). The mobile phase A was $0.1 \%$ formic acid in water for positive, and $5 \mathrm{mmol} / \mathrm{L}$ ammonium acetate in water for negative, and the mobile phase $\mathrm{B}$ was acetonitrile. The elution gradient was set as follows: 0 min, 1\% B; 1 min, 1\% B; 8 min, 99\% B; $10 \mathrm{~min}, 99 \% \mathrm{~B} ; 10.1 \mathrm{~min}, 1 \% \mathrm{~B}$; and $12 \mathrm{~min}$, $1 \% \mathrm{~B}$. The flow rate was $0.5 \mathrm{~mL} / \mathrm{min}$. The injection volume was $3 \mu \mathrm{L}$. The QE mass spectrometer was used because of its ability to acquire MS/MS spectra on an information-dependent basis (IDA) during an LC/MS experiment. In this mode, the acquisition software (Xcalibur 4.0.27, Thermo Fisher Scientific) continuously evaluates the full scan survey MS data as it collects and triggers the acquisition of MS/MS spectra depending on preselected criteria. ESI source conditions were set as follows: Sheath gas flow rate as 45 Arb, Aux gas flow rate as $15 \mathrm{Arb}$, capillary temperature $400{ }^{\circ} \mathrm{C}$, full $\mathrm{ms}$ resolution as 70,000 , MS/MS resolution as 17,500 , collision energy as $20 / 40 / 60 \mathrm{eV}$ in NCE model, and spray voltage as $4.0 \mathrm{kV}$ (positive) or $-3.6 \mathrm{kV}$ (negative), respectively.

The raw data were converted to the mzXML format using ProteoWizard and processed using MAPS software (Version 1.0). The preprocessing results generated a data matrix that consisted of the retention time (RT), masstocharge ratio $(\mathrm{m} / \mathrm{z})$ values, and peak intensity. In-house MS2 database was applied for metabolite identification.

\section{MTT assay}

At $72 \mathrm{~h}$ after osteogenic differentiation under different treatment conditions, $20 \mu \mathrm{L}$ MTT [3-(4,5-dimethylthiazol-2-yl)-2,5-diphenyltetrazolium bromide)] solution $(5 \mathrm{~g} / \mathrm{L})$ was added to each well of the 96-well plates, and cells were incubated for another $4 \mathrm{~h}$ in the incubator (37 ${ }^{\circ} \mathrm{C}$ and $5 \% \mathrm{CO}_{2}$ ). The medium in each well was aspirated and $100 \mu \mathrm{l}$ of DMSO was added. Cell viability was quantified by measuring absorbance at $490 \mathrm{~nm}$ on a microplate reader. The optical density (OD) values of samples in experimental groups were normalized to that of the control groups without $\mathrm{H}_{2} \mathrm{O}_{2}$ or drug treatments at the same time point.

\section{Measurement of intracellular peroxide markers}

The reactive oxygen species (ROS) test kit was purchased from Beyotime Biotechnology (Shanghai, China). The SOD (superoxide dismutase), MDA (malondialdehyde), and GSH-PX (glutathione peroxidase) test kits were obtained from Nanjing Institute of Bioengineering Research Institute (Nanjing, China). Assays to measure intracellular ROS and MDA levels, as well as SOD and GSH-PX activity of BMSCs were conducted following the manufacturer's protocols. Briefly, after removing the medium, $10 \mu \mathrm{mol} / \mathrm{L}$ DFCH-DA diluted in serum-free medium was added to each group of cells and incubated 
at $37{ }^{\circ} \mathrm{C}$ for $20 \mathrm{~min}$ in the dark. Then, the cells were washed three times with serum-free cell culture medium, and the fluorescence intensity of each well was detected using a fluorescence microplate reader at an excitation wavelength of $488 \mathrm{~nm}$ to calculate intracellular ROS levels. To determine SOD activity, total protein was extracted and the protein concentration was determined using the BCA method. The SOD inhibition rate was calculated according to the formula provided by the manufacturer. To determine MDA levels, the homogenate of treated cells was prepared, and the MDA value was calculated using a colorimetric measurement of each tube at $532 \mathrm{~nm}$ after the addition of the reagents. To detect GSH-PX activity, absorbance of the samples was determined at $412 \mathrm{~nm}$ at the end of the reaction using a microplate reader. All results were calculated according to the manuals provided with the kits.

\section{Cell cycle analysis}

Cells were fixed with $70 \%$ ethanol at $4{ }^{\circ} \mathrm{C}$ overnight. After centrifugation at $1500 \mathrm{rpm}$ for $5 \mathrm{~min}$ and two washes with PBS, cells were incubated with $0.1 \mathrm{mg} / \mathrm{mL}$ RNase A (Thermo Fisher Scientific) at $37^{\circ} \mathrm{C}$ for $30 \mathrm{~min}$ and then $0.05 \mathrm{mg} / \mathrm{ml}$ propidium iodide (PI) at $4{ }^{\circ} \mathrm{C}$ for another $30 \mathrm{~min}$. The DNA content was determined using a flow cytometer (FACSCalibur, BD Biosciences; Franklin Lakes, NJ, USA), and 2-3 million cells were collected. Data were analyzed using the Modfit LT software (Verity Software House).

\section{Osteogenesis-related gene expression}

Total RNA was extracted using the Extreme RNA extraction kit (HaiGene; Harbin, China) following the manufacturer's protocols. The quality of the total RNA was evaluated by the electrophoresis of the agarose gels, and the concentration of total RNA was measured using an ND5000 ultra-micro UV spectrophotometer. After that, the total RNA was reverse transcribed to cDNA using Golden 1st cDNA Synthesis Kit (HaiGene) followed the manufacturer's manual. In detail, $1 \mu \mathrm{g}$ of the total RNA was used in $20 \mu \mathrm{l}$ of the reverse transcription reaction by mixing $4 \mu \mathrm{l}$ of the $5 \times$ concentrated RT MasterMix (which contained the reaction buffer, MLV Reverse transcriptase, RNase Inhibitor, dNTPs, and $\mathrm{Mg}^{2+}$ ), $1 \mu \mathrm{l}$ of $20 \times$ concentrated primer mixture of oligo $\mathrm{dT}$ and random hexamer primers, and distilled water. RNA was converted to cDNA following the reaction conditions: 25 ${ }^{\circ} \mathrm{C}$ for $5 \mathrm{~min}, 55^{\circ} \mathrm{C}$ for $30 \mathrm{~min}$, and $85{ }^{\circ} \mathrm{C}$ for $5 \mathrm{~min}$. Then, $100 \mathrm{ng}$ of the cDNA was used for quantitative real-time PCR (RT-qPCR) reaction on a fluorescence quantitative PCR system using SYBR Green Fluorescence Quantification PCR Kit (HaiGene). The reaction conditions were $15 \mathrm{~min}$ at $95{ }^{\circ} \mathrm{C}, 40$ cycles of $10 \mathrm{~s}$ at 95 ${ }^{\circ} \mathrm{C}$, and $30 \mathrm{~s}$ at $60{ }^{\circ} \mathrm{C}$. The relative expression levels of each gene were analyzed using the $2^{-\Delta \Delta C t}$ method and normalized to GAPDH expression. The sequences of primers for each gene were as follows:

ALP, 5' -CGGCGGATGATAAGGAGGAC-3' (forward), 5'-GGCGTGTAACAGATGGAAACC-3' (reverse); Collagen I, 5' -AAGGGGTGGGGTGGGAAG-3' (forward),

5'-GAGAGCAGGCTGGAGTTGG-3' (reverse);

Osteopontin (OPN), 5'-GCTTGGCTTACGGACTGA GG-3' (forward),

5' -CTGGGCAACTGGGATGACC-3' (reverse);

Runx2, 5'-GCGGAACAACAACAACAACAAC-3' (forward),

5' -GAAAGCAAATCTTGGGCAATAGC-3' (reverse); GAPDH, 5' -AACTCCCATTCTTCCACCTTT-3' (forward),

$$
\text { 5'-CTCTTGCTCTCAGTATCCTTG-3' (reverse). }
$$

\section{Alkaline phosphatase (ALP) activity assays}

ALP activity was detected using the ALP activity kit (Solarbio; Beijing, China) according to the manufacturer's protocol. Briefly, BMSCs were fixed with the ALP fixative for $3 \mathrm{~min}$. Then, the ALP incubation solution was added, and cells were incubated in the wet box for $20 \mathrm{~min}$ in dark. After washing with distilled water, the stained cells were visualized under a microscope and photographed.

Quantifying matrix mineralization via alizarin red staining Matrix mineralization was evaluated using alizarin red $\mathrm{S}$ staining. At 21 days after BMSC osteogenic differentiation under the indicated conditions, cells were washed twice with PBS and fixed with $4 \%$ paraformaldehyde for $30 \mathrm{~min}$ at $25{ }^{\circ} \mathrm{C}$. Then, the cells were stained with $1 \%$ Alizalin Red ( $\mathrm{pH}$ 4.2; Solarbio; Beijing, China) for 30 min and visualized under a microscope and photographed as previously described [30].

\section{Western blot analysis}

Total protein was extracted from the treated cells with RIPA (radioimmunoprecipitation assay) lysis buffer and the total protein concentration was determined using a BCA assay kit (Beyotime; Shanghai, China). Protein samples in loading buffer were heated at $100{ }^{\circ} \mathrm{C}$ for $5 \mathrm{~min}$, and an equal amount of protein for each sample was loaded onto $12 \%$ polyacrylamide gels (Beyotime Biotechnology). After electrophoresis, proteins were transferred onto polyvinylidene difluoride membranes. The membranes were blocked with 5\% BSA and incubated with the primary antibodies overnight a $4{ }^{\circ} \mathrm{C}$ and the secondary antibody for $1 \mathrm{~h}$ at room temperature. The primary antibodies were as follows: anti-caspase-3 (1:1,000 dilution; Cell Signaling Technology; Danvers, MA, USA), anti-Akt (1:1,000 dilution; Cell Signaling Technology), 
anti-phosphorylated (p)-Akt (1:2,000 dilution; Cell Signaling Technology), anti-Foxo1 (1:1,000 dilution; Cell Signaling Technology), and anti-GAPDH (Zhongshan Golden Bridge Biotechnology Co., Ltd., Beijing, China). Antibodies were diluted in Tris-buffered saline with $0.1 \%$ Tween-20 (pH 7.6, $20 \mathrm{mM}$ Tris and $150 \mathrm{mM} \mathrm{NaCl}$; TBS-T). Secondary antibodies including goat anti-mouse $(\mathrm{H}+\mathrm{L}) / \mathrm{HRP}$ (horseradish peroxidase) (1:5,000 dilution) and goat anti-mouse $(\mathrm{H}+\mathrm{L}) / \mathrm{HRP}(1: 5,000$ dilution) were purchased from Zhongshan Golden Bridge Biotechnology Co., Ltd. (Beijing, China). Proteins of interest were visualized using the Supersensitive ECL (enhanced chemiluminescence) Primer kit purchased from HaiGene (Harbin, China). Signals were detected using an Imaging
System (Clinx; Shanghai, China) and data are expressed as normalized ratios to GAPDH.

\section{Statistical analysis}

The experimental results are expressed as mean \pm standard deviation (mean $\pm \mathrm{SD}$ ), and statistical analysis was performed using the SPSS 24.0 software (IBM, Armonk, NY, USA). One-way analysis of variance (one-way ANOVA) was used to compare multiple-sample groups. Differences between groups were analyzed by Tukey's post hoc test (Figs. 1, 2, 3a, c, d, and 4) or Dunnett's T3 test (Fig. 3b). Differences were statistically significant at $P<0.05$.th $=$ tlb $=$

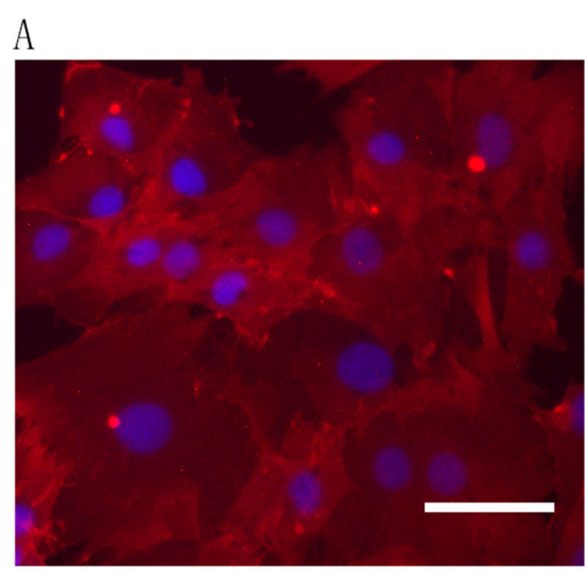

CD44 positive (100X)

C

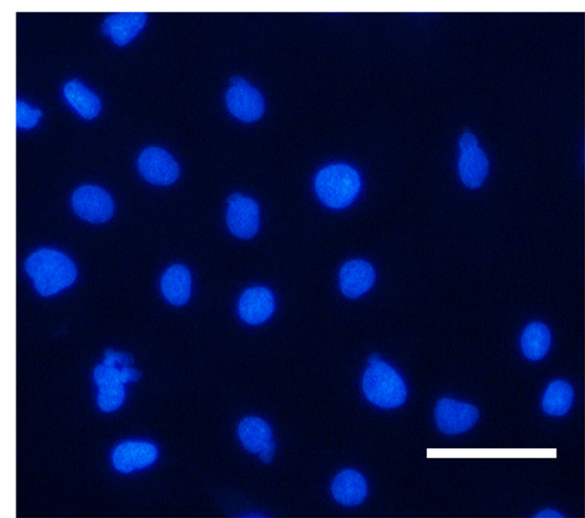

CD31 negative $(100 \times)$
B

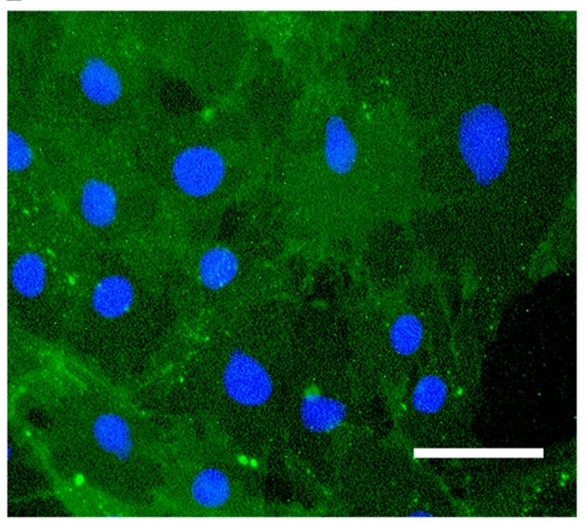

CD90 positive $(100 \times)$

D

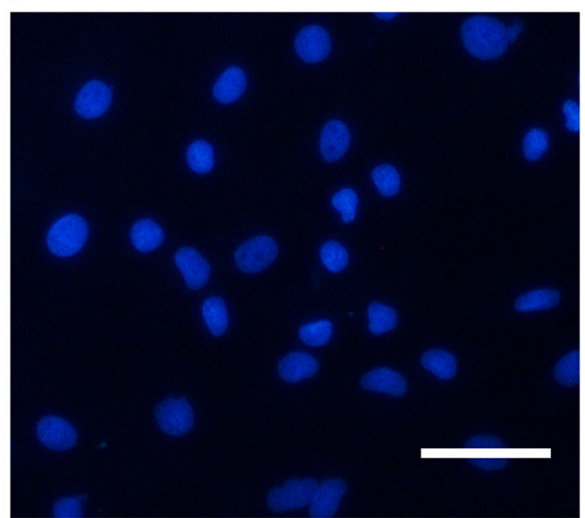

CD34 negative $(100 \times)$

Fig. 1 Moringa oleifera attenuates $\mathrm{H}_{2} \mathrm{O}_{2}$-induced dysregulation of cell viability and cell cycle progression in BMSCs during osteogenic differentiation. a The effects of $\mathrm{H}_{2} \mathrm{O}_{2}$ at indicated concentrations and treatment times on cell viability in $\mathrm{P} 3$ cells. $\mathrm{H}_{2} \mathrm{O}_{2} 50$, cells treated with 50 $\mu \mathrm{mol} / \mathrm{L} \mathrm{H}_{2} \mathrm{O}_{2} ; \mathrm{H}_{2} \mathrm{O}_{2} 100$, cells treated with $100 \mu \mathrm{mol} / \mathrm{L} \mathrm{H}_{2} \mathrm{O}_{2} ; \mathrm{H}_{2} \mathrm{O}_{2} 200$, cells treated with $200 \mu \mathrm{mol} / \mathrm{L} \mathrm{H}_{2} \mathrm{O}_{2} .{ }^{*} P<0.05$ compared with the control group; ${ }^{\# P}<0.05$ compared with the $\mathrm{H}_{2} \mathrm{O}_{2} 50$ group; ${ }^{@} P<0.05$ compared with the $\mathrm{H}_{2} \mathrm{O}_{2} 100$ group. b. c The effects of $\mathrm{H}_{2} \mathrm{O}_{2}$ and Moringa oleifera on cell viability and cell cycle progression of BMSCs during osteogenic differentiation. Cell viability (b) and cell cycle progression (c) of the indicated groups were measured at $48 \mathrm{~h}$ after initiation of osteogenic differentiation. Representative flow profile of cell cycle progression and percentage of cells in the $\mathrm{G} 2+\mathrm{S}$ phases are shown. $\mathrm{N}=3$ for each group; ${ }^{*} P<0.05$ compared with the control group; ${ }^{\# P}<0.05$ compared with the $\mathrm{MO}$ group; ${ }^{@} \mathrm{P}<0.05$ compared with the $\mathrm{OS}+\mathrm{H}_{2} \mathrm{O}_{2}$ group 


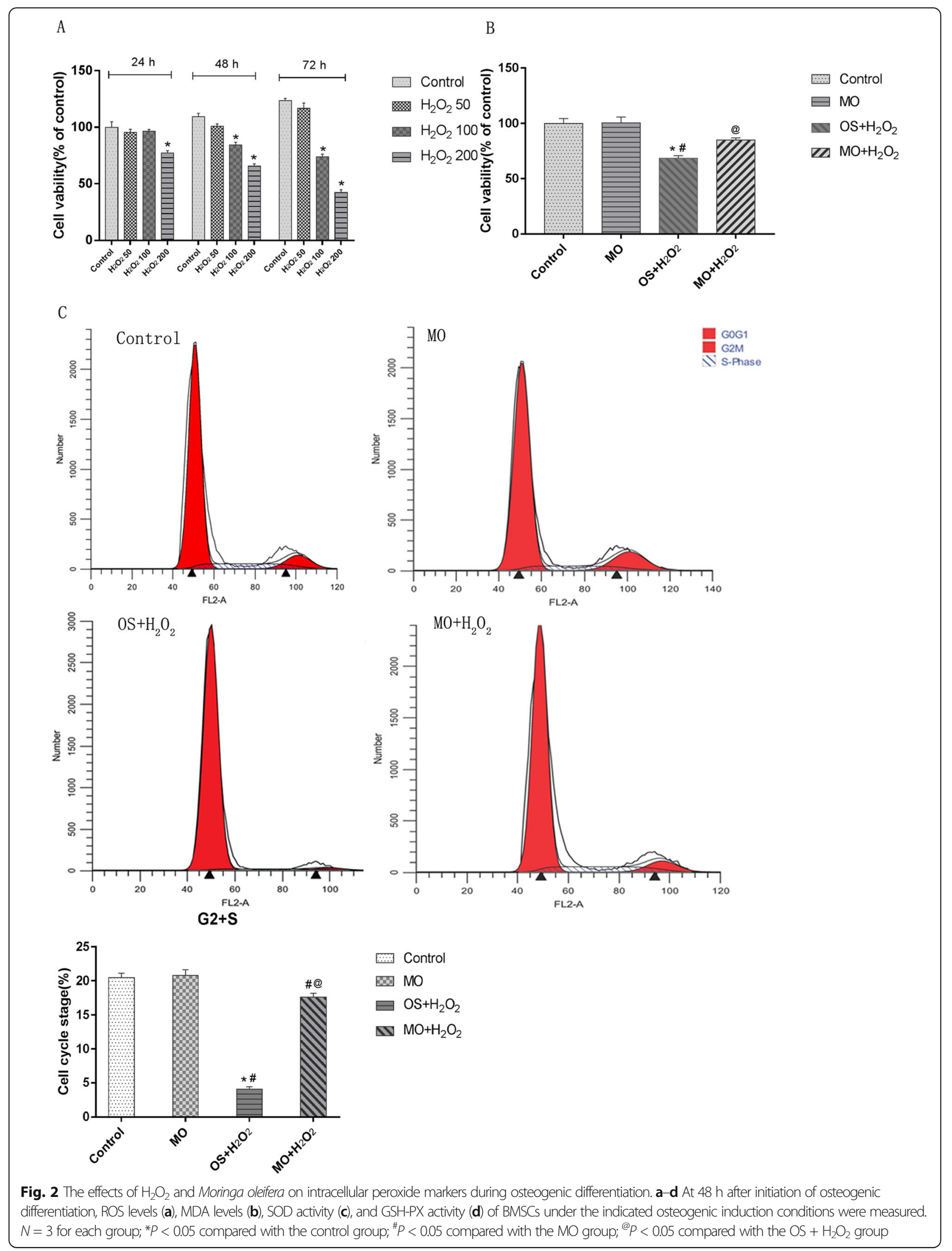




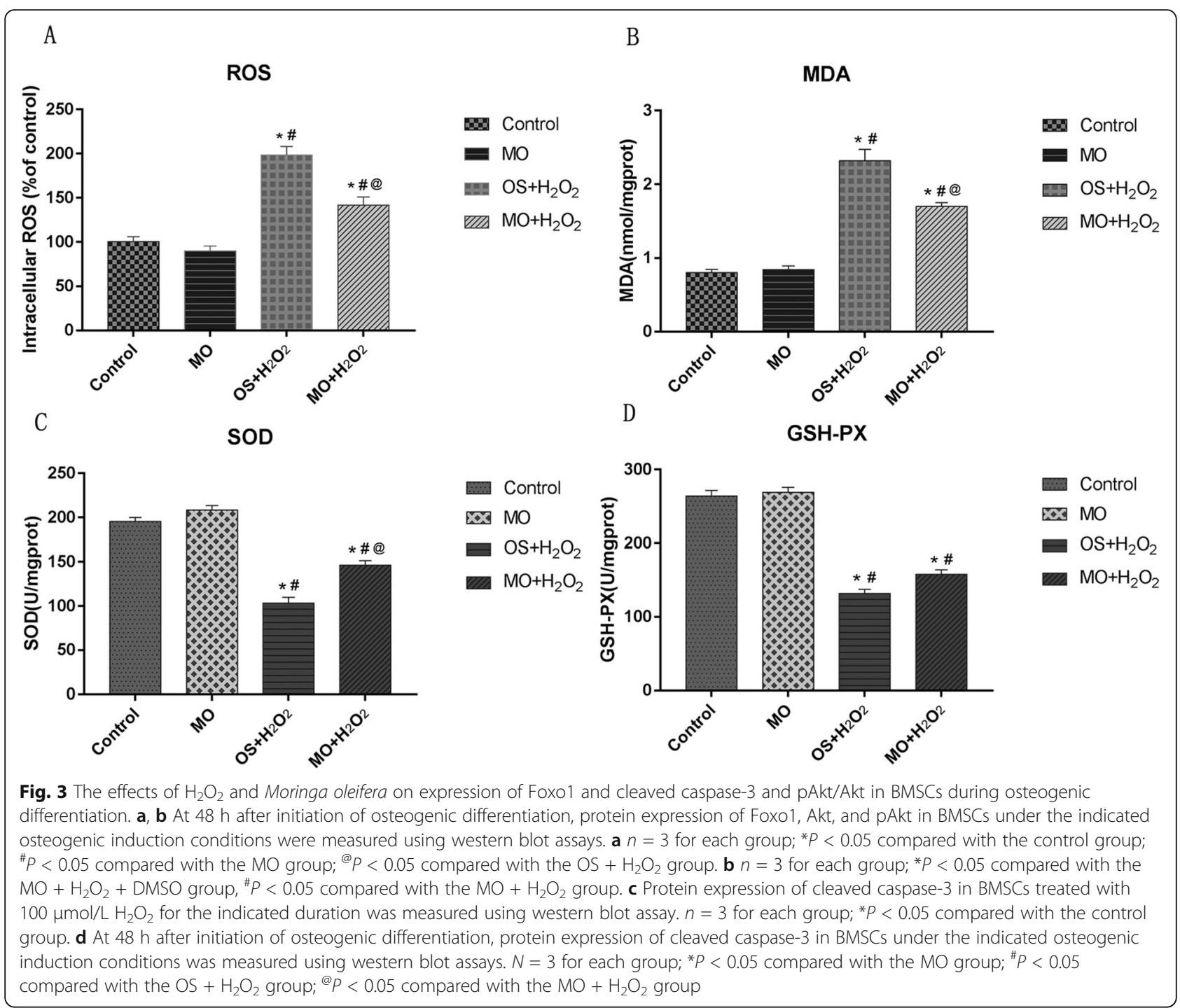

\section{Results}

The effects of $\mathrm{H}_{2} \mathrm{O}_{2}$ and Moringa oleifera on cell viability and cell cycle progression of BMSCs during osteogenic differentiation

The P3 cells (3rd generation of primary rat BMSCs) with good growth status were used for in vitro experiments. These BMSCs were confirmed to be $\mathrm{CD} 44^{+} \mathrm{CD} 90^{+}$ $\mathrm{CD}^{-} 1^{-} \mathrm{CD}^{-} 4^{-}$using immunofluorescence antibody staining (Fig. 5a-d). To test the therapeutic effects of Moringa oleifera during BMSC osteogenic differentiation, we first sought to establish a BMSCs damage model. The P3 cells were treated with $\mathrm{H}_{2} \mathrm{O}_{2}$ at the concentrations of $50 \mu \mathrm{mol} / \mathrm{L}, 100 \mu \mathrm{mol} / \mathrm{L}$, and $200 \mu \mathrm{mol} / \mathrm{L}$ for 24,48 , and $72 \mathrm{~h}$, separately. Cell viability was measured to evaluate cellular damage. As shown in Fig. 1a, no significant difference was observed in cell viability of BMSCs treated with $50 \mu \mathrm{mol} / \mathrm{L}$ and $100 \mu \mathrm{mol} / \mathrm{L}$ doses of $\mathrm{H}_{2} \mathrm{O}_{2}$ for $24 \mathrm{~h}$ or $50 \mu \mathrm{mol} / \mathrm{L} \mathrm{H}_{2} \mathrm{O}_{2}$ for $48 \mathrm{~h}$ and $72 \mathrm{~h}$.
Cell viability of BMSCs treated for $48 \mathrm{~h}$ significantly decreased upon $\mathrm{H}_{2} \mathrm{O}_{2}$ challenge, and further decreased in response to $200 \mu \mathrm{mol} / \mathrm{L} \mathrm{H}_{2} \mathrm{O}_{2}\left(P_{200}\right.$ vs Control $\left.<0.001\right)$. Cell viability decreased in BMSCs treated with 100 $\mu \mathrm{mol} / \mathrm{L}_{2} \mathrm{O}_{2}$ for $48 \mathrm{~h}\left(P_{100}\right.$ vs Control $\left.=0.006\right)$. According to the above results, BMSCs treated with $100 \mu \mathrm{mol} /$ $\mathrm{L}_{2} \mathrm{O}_{2}$ were selected for subsequent experiments, and the P3 cells were treated for either 48 h, 7 days, or 21 days.

We next evaluated the impact of Moringa oleifera on attenuating dysregulated cell viability and cell cycle progression of BMSCs treated with $100 \mu \mathrm{mol} / \mathrm{L} \mathrm{H}_{2} \mathrm{O}_{2}$. To better mimic the clinical pharmacodynamic property of Moringa oleifera in patients, we treated BMSCs with drug-containing serum from rats administrated the Moringa leaf for three consecutive days. The non-target UHPLC-QE-MS analysis confirmed the existence of Moringa oleifera in the serum (Fig. 6). After treatment 


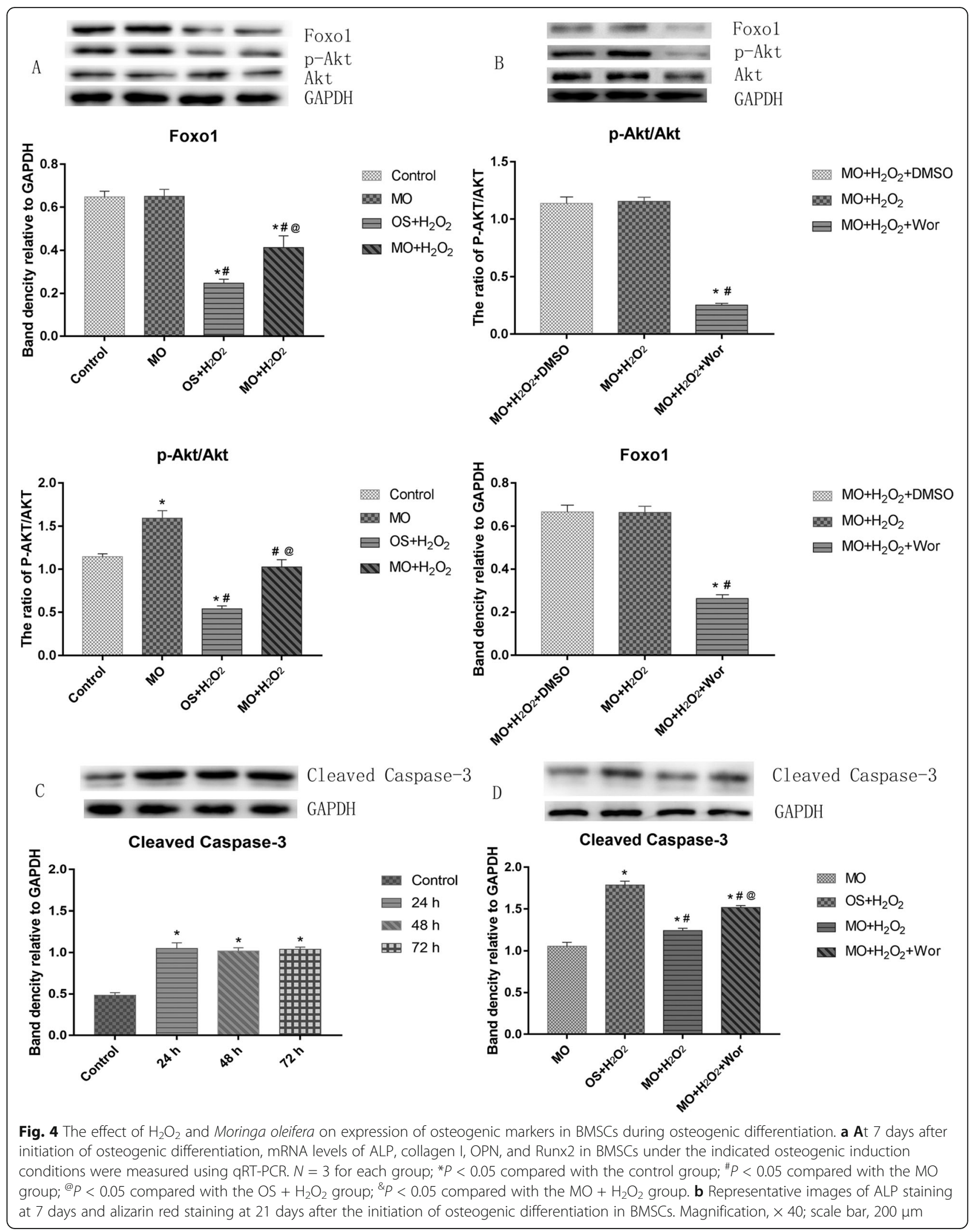


Table 1 The experimental groups and treatments

\begin{tabular}{|c|c|c|}
\hline Group & Medium & Treatment \\
\hline Control & Osteogenic differentiation medium & No \\
\hline MO & $\begin{array}{l}\text { Osteogenic differentiation medium + 10\% Moringa leaf-containing } \\
\text { serum }\end{array}$ & No \\
\hline $\mathrm{OS}+\mathrm{H}_{2} \mathrm{O}_{2}$ & Osteogenic differentiation medium & $100 \mu \mathrm{mol} / \mathrm{L} \mathrm{H}_{2} \mathrm{O}_{2}$ \\
\hline $\mathrm{MO}+\mathrm{H}_{2} \mathrm{O}_{2}$ & $\begin{array}{l}\text { Osteogenic differentiation medium + 10\% Moringa leaf-containing } \\
\text { serum }\end{array}$ & $100 \mu \mathrm{mol} / \mathrm{L}$ of $\mathrm{H}_{2} \mathrm{O}_{2}$ \\
\hline $\mathrm{MO}+\mathrm{H}_{2} \mathrm{O}_{2}+$ Wor & $\begin{array}{l}\text { Osteogenic differentiation medium + 10\% Moringa leaf-containing } \\
\text { serum }\end{array}$ & $100 \mu \mathrm{mol} / \mathrm{L} \mathrm{H}_{2} \mathrm{O}_{2}$ and $0.5 \mu \mathrm{mol} / \mathrm{L}$ wortmannin \\
\hline $\mathrm{MO}+\mathrm{H}_{2} \mathrm{O}_{2}+\mathrm{DMSO}$ & $\begin{array}{l}\text { Osteogenic differentiation medium + 10\% Moringa leaf-containing } \\
\text { serum }\end{array}$ & $\begin{array}{l}100 \mu \mathrm{mol} / \mathrm{L} \mathrm{H} \mathrm{H}_{2}, 0.5 \mu \mathrm{mol} / \mathrm{L} \text { of wortmannin and DMSO } \\
\text { (its dosage was the same as the } \mathrm{MO}+\mathrm{H}_{2} \mathrm{O}_{2}+\text { Wor group) }\end{array}$ \\
\hline
\end{tabular}

OS the third passage of BMSCs were cultured in osteogenic differentiation medium, MO the third passage of BMSCs were cultured in osteogenic differentiation medium $+10 \%$ Moringa leaf-containing serum, Wor wortmannin, an inhibitor of PI3K, DMSO solvent of wortmannin

for $48 \mathrm{~h}$, BMSCs demonstrated significant differences in cell viability and proliferation (as indicated by the percentage of cells in the $\mathrm{G} 2+\mathrm{S}$ phases of cell cycle progression) among the control, $\mathrm{MO}, \mathrm{OS}+\mathrm{H}_{2} \mathrm{O}_{2}$, and $\mathrm{MO}$ $+\mathrm{H}_{2} \mathrm{O}_{2}$ groups. Cell viability (Fig. $1 \mathrm{~b}$ ) and proliferation (Fig. 1c) in the control and $\mathrm{MO}$ groups were significantly higher compared to the $\mathrm{OS}+\mathrm{H}_{2} \mathrm{O}_{2}$ groups (all $P \leq$ $0.05)$. Compared to the control group, cell viability and proliferation were not altered in the $\mathrm{MO}$ group. Notably, compared to the $\mathrm{OS}+\mathrm{H}_{2} \mathrm{O}_{2}$ group, cell viability and proliferation in the $\mathrm{MO}+\mathrm{H}_{2} \mathrm{O}_{2}$ group improved significantly (all $P \leq 0.05$ ), suggesting that Moringa oleifera can significantly reduce $\mathrm{H}_{2} \mathrm{O}_{2}$-mediated damage of BMSCs.

\section{The effect of $\mathrm{H}_{2} \mathrm{O}_{2}$ and Moringa oleifera on intracellular peroxidative markers of $\mathrm{BMSC}$ osteogenic differentiation} Next, we evaluated the effects of $\mathrm{H}_{2} \mathrm{O}_{2}$ and Moringa oleifera on BMSC intracellular peroxide markers, including ROS and MDA levels, as well as SOD and GSH-PX activity. During BMSC osteogenic differentiation, significant differences were identified in these parameters among the four groups (Fig. 2). ROS (Fig. 2a) and MDA (Fig. 2b) levels in the control and $\mathrm{MO}$ groups were significantly lower compared to the $\mathrm{OS}+\mathrm{H}_{2} \mathrm{O}_{2}$ and $\mathrm{MO}+\mathrm{H}_{2} \mathrm{O}_{2}$ groups (all $P \leq 0.001$ ), while SOD (Fig. 2c) and GSH-PX (Fig. 2d) activity in the OS $+\mathrm{H}_{2} \mathrm{O}_{2}$ and $\mathrm{MO}+\mathrm{H}_{2} \mathrm{O}_{2}$ groups were significantly lower compared to the Control and MO groups (all $P \leq 0.001$ ).

No significant differences were found in ROS and MDA levels, as well as SOD and GSH-PX activity between the control and MO groups. ROS and MDA levels in the MO $+\mathrm{H}_{2} \mathrm{O}_{2}$ groups were significantly lower compared to the OS $+\mathrm{H}_{2} \mathrm{O}_{2}$ group (all $P<0.05$ ). In contrast, SOD and GSH-PX activity in the $\mathrm{MO}+\mathrm{H}_{2} \mathrm{O}_{2}$ groups were significantly higher compared to the $\mathrm{OS}+\mathrm{H}_{2} \mathrm{O}_{2}$ group (all $P<$ 0.05), except $P_{\text {GSH-PX }}=0.099$. Collectively, these results suggest that Moringa oleifera can significantly alleviate the intracellular $\mathrm{H}_{2} \mathrm{O}_{2}$-mediated perturbations in BMSCs.
The effects of $\mathrm{H}_{2} \mathrm{O}_{2}$ and Moringa oleifera on Foxo1 and cleaved caspase-3 expression and the ratio of pAkt/Akt in BMSCs during osteogenic differentiation

Since the PI3K/Akt signaling pathway is critically involved in BMSC osteogenic differentiation [31], we evaluated the effects of $\mathrm{H}_{2} \mathrm{O}_{2}$ and Moringa oleifera in regulating the expression levels of Foxo1 and pAkt, two downstream targets of the PI3K/Akt pathway. There were significant differences in the expression levels of Foxo1 and the ratios of pAkt/Akt among the four groups (Fig. 3a). The ratio of pAkt/Akt in the MO group was significantly higher compared to the other groups (all $P$ $<0.05$, Fig. 3a), while the expression of Foxo1 and the pAkt/Akt ratio were lowest in the $\mathrm{OS}+\mathrm{H}_{2} \mathrm{O}_{2}$ group (all $P<0.05$, Fig. 3a). No significant differences were found in the pAkt/Akt ratio between the control group and the $\mathrm{MO}+\mathrm{H}_{2} \mathrm{O}_{2}$ group, or in Foxo1 expression between the control group and the MO group (Fig. 3a).

To substantiate the role of PI3K/Akt signaling in the protective effect of Moringa oleifera, we treated BMSCs in the $\mathrm{MO}+\mathrm{H}_{2} \mathrm{O}_{2}$ group with the vehicle DMSO or the PI3K inhibitor wortmannin. As shown in Fig. 3b, DMSO had no effect on Akt and Foxo1 expression, while the pAkt/Akt ratio and Foxo1 expression in the $\mathrm{MO}+\mathrm{H}_{2} \mathrm{O}_{2}$ + Wor group were significantly lower compared to the $\mathrm{MO}+\mathrm{H}_{2} \mathrm{O}_{2}$ or $\mathrm{MO}+\mathrm{H}_{2} \mathrm{O}_{2}+$ DMSO group (all $P<$ $0.001)$.

PI3K/Akt signaling also plays an important role in survival pathways by inactivating downstream apoptotic factors. Therefore, we further examined whether the protective effect of Moringa oleifera was associated with reduced apoptosis in BMSCs stimulated with $\mathrm{H}_{2} \mathrm{O}_{2}$. First, we detected expression of cleaved caspase-3 in BMSCs treated with $100 \mu \mathrm{mol} / \mathrm{L} \mathrm{H}_{2} \mathrm{O}_{2}$ for different durations. As shown in Fig. 3c, $\mathrm{H}_{2} \mathrm{O}_{2}$ at all tested durations $(24,48$, and $72 \mathrm{~h})$ induced significantly higher expression of cleaved caspase- 3 compared to the control group (Fig. 


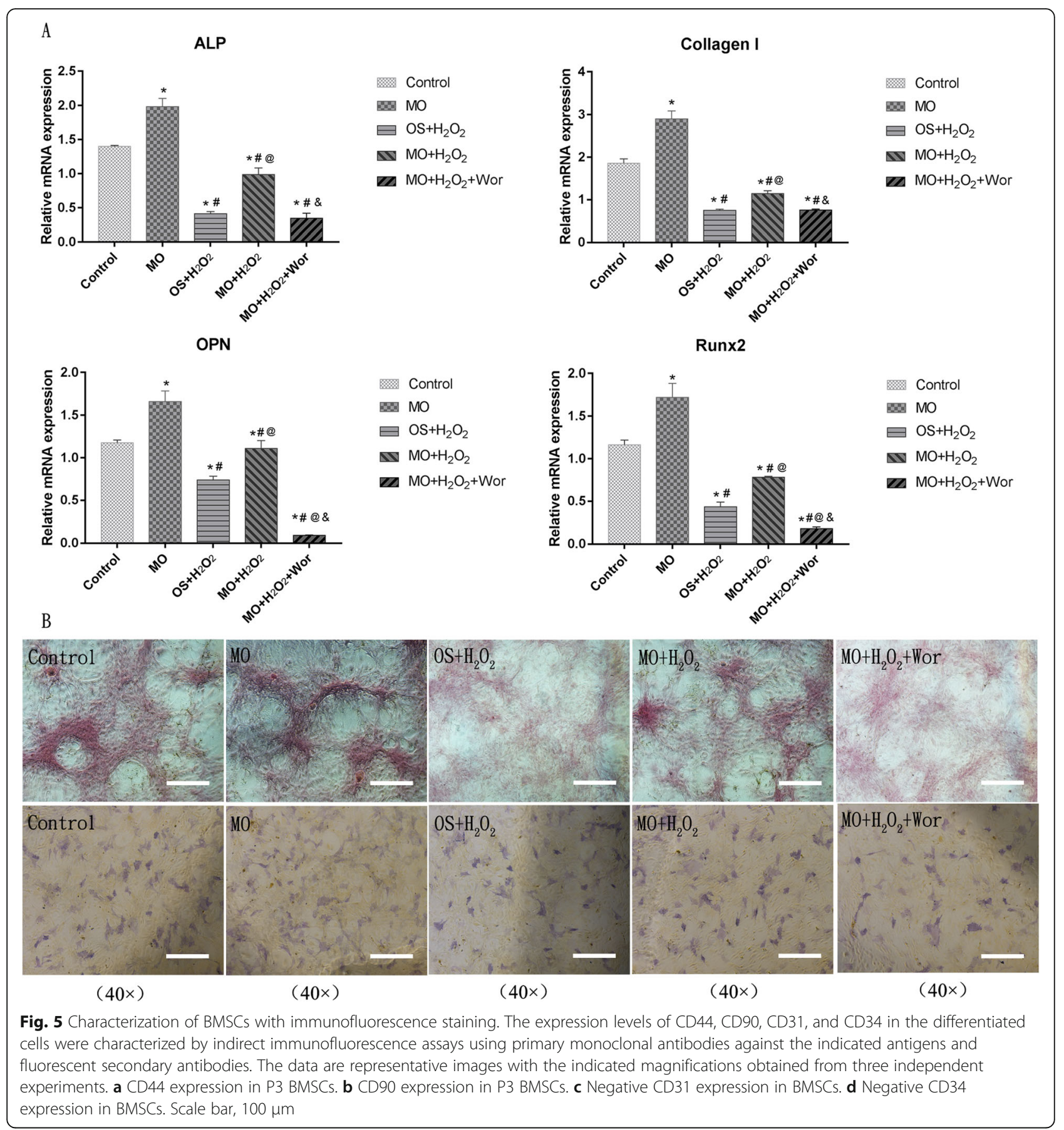

3c). However, no significant difference was found among the groups with different treatment durations.

We then examined the impact of $\mathrm{H}_{2} \mathrm{O}_{2}$, Moringa oleifera, and wortmannin, alone or in combination, on cleaved caspase- 3 expression in BMSCs during osteogenic differentiation. As shown in Fig. 3d, there were significant differences in the expression of cleaved caspase-3 among different treatment groups. Cleaved caspase-3 expression was highest in the $\mathrm{OS}+\mathrm{H}_{2} \mathrm{O}_{2}$ group $(P<0.05)$, and lowest in the MO group (all $P<$ 0.05). Compared to the $\mathrm{MO}+\mathrm{H}_{2} \mathrm{O}_{2}$ group, cleaved caspase-3 expression was higher in the $\mathrm{OS}+\mathrm{H}_{2} \mathrm{O}_{2}$ group and $\mathrm{MO}+\mathrm{H}_{2} \mathrm{O}_{2}+$ Wor group (all $P<0.05$ ). Taken together, these results indicate that Moringa 


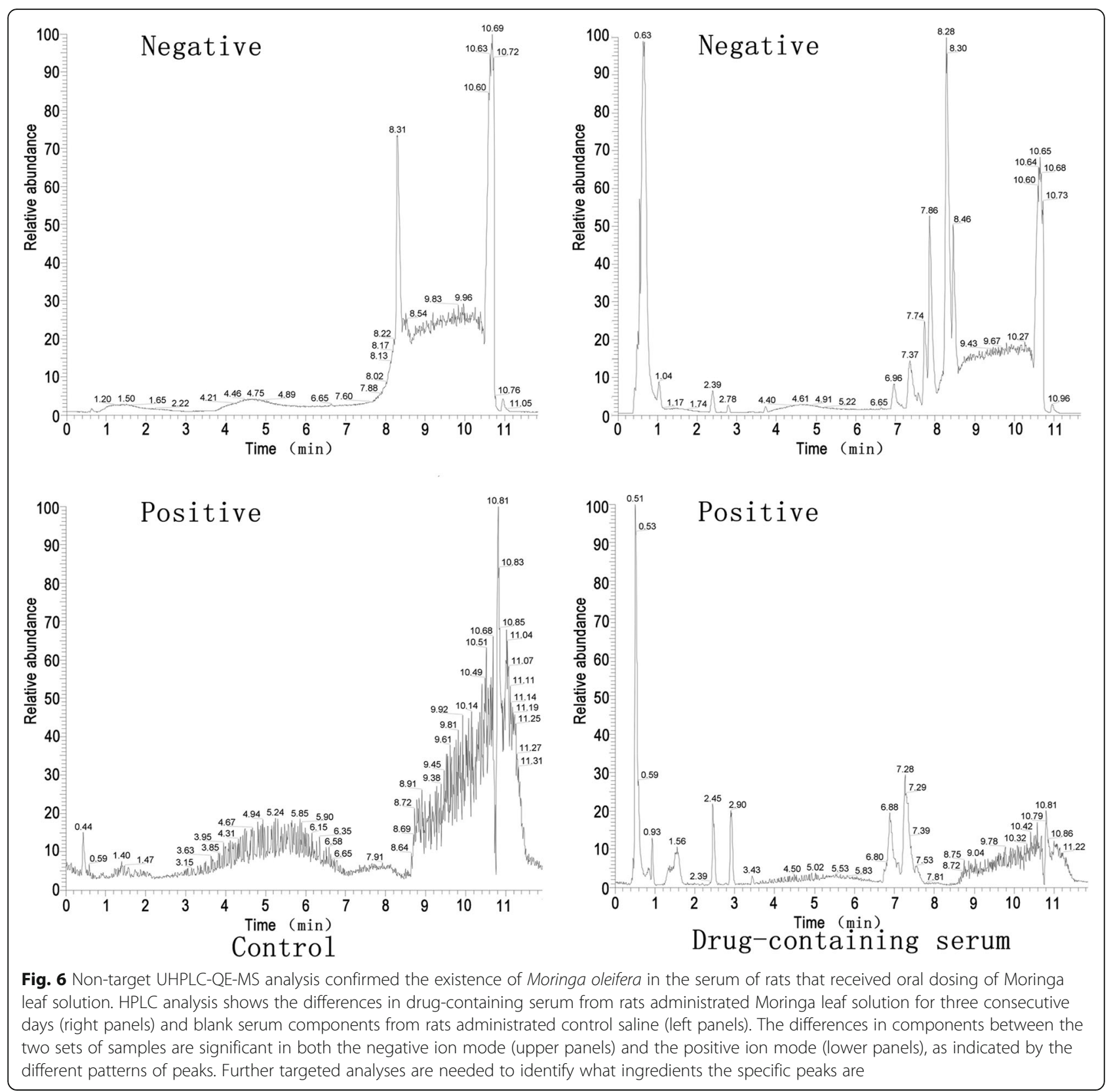

oleifera exerts protective effects upon $\mathrm{H}_{2} \mathrm{O}_{2}$-induced damage of BMSCs through enhancing PI3K/Akt signaling and reducing BMSC apoptosis.

\section{The effect of $\mathrm{H}_{2} \mathrm{O}_{2}$ and Moringa oleifera on the expression of osteogenic markers in BMSCs during osteogenic differentiation}

We also evaluated the impact of $\mathrm{H}_{2} \mathrm{O}_{2}$, Moringa oleifera, and wortmannin on the expression levels of osteogenic genes (ALP, collagen I, OPN, and Runx2) in BMSCs. As shown in Fig. 4a, after 7 days of treatment, there were significant differences in gene expression among the control, $\mathrm{MO}$, $\mathrm{OS}+\mathrm{H}_{2} \mathrm{O}_{2}, \mathrm{MO}+\mathrm{H}_{2} \mathrm{O}_{2}$, and $\mathrm{MO}+\mathrm{H}_{2} \mathrm{O}_{2}$
+ Wor groups. Expression levels of ALP, collagen I, and Runx2 in the Control group were higher compared to the $\mathrm{OS}+\mathrm{H}_{2} \mathrm{O}_{2}$ and $\mathrm{MO}+\mathrm{H}_{2} \mathrm{O}_{2}$ group (all $P<0.05$ ). Compared to the control group, OPN expression in the $\mathrm{OS}+\mathrm{H}_{2} \mathrm{O}_{2}$ group decreased significantly $(P=0.007)$, while additional Moringa oleifera treatment $(\mathrm{MO}+$ $\mathrm{H}_{2} \mathrm{O}_{2}$ group) significantly reversed this decrease $(P<$ 0.05).

The expression levels of four osteogenic markers in the $\mathrm{MO}+\mathrm{H}_{2} \mathrm{O}_{2}$ group were higher compared to those in the OS+ $\mathrm{H}_{2} \mathrm{O}_{2}$ group. No evident changes in ALP, collagen I, or Runx2 expression were identified between the $\mathrm{OS}+\mathrm{H}_{2} \mathrm{O}_{2}$ and the $\mathrm{OS}+\mathrm{H}_{2} \mathrm{O}_{2}+$ Wor groups, 
suggesting that wortmannin can eliminate the protective effects of Moringa oleifera in terms of promoting osteogenic gene expression. In addition, compared to the OS $+\mathrm{H}_{2} \mathrm{O}_{2}+$ Wor group, expression levels of ALP, collagen I, OPN, and Runx2 in the control, $\mathrm{MO}$, and $\mathrm{MO}+\mathrm{H}_{2} \mathrm{O}_{2}$ groups were significantly higher (all $P<0.05$ ). Expression levels of ALP, collagen I, OPN, and Runx2 in the $\mathrm{MO}$ group were significantly higher compared to all other groups (all $P<0.05$ ).

Furthermore, the improvement in BMSC osteogenic differentiation by Moringa oleifera was confirmed through ALP staining and alizarin red staining in the above mentioned five groups. ALP staining was performed after culturing the P3 cells for 7 days. The number of blue stained cells in the $\mathrm{MO}+\mathrm{H}_{2} \mathrm{O}_{2}$ group was higher compared to the $\mathrm{OS}+\mathrm{H}_{2} \mathrm{O}_{2}$ group, while the number of positively stained cells in the $\mathrm{MO}$ group was the highest. Wortmannin significantly reduced the number of positively stained cells cultured in the medium with $\mathrm{MO}+\mathrm{H}_{2} \mathrm{O}_{2}$ (Fig. 4b). Alizarin red staining was carried out at 21 days after initiation of osteogenic differentiation, and the results were consistent with the ALP staining (Fig. 4b).

\section{Discussion}

Cell peroxidation is an important factor in aging and various chronic diseases. Research in the last 20 years has revealed that oxidative stress plays central roles in the etiology of osteoporosis [32]. In this study, we established a model of peroxidative damage in rat BMSCs undergoing osteogenic differentiation and evaluated the protective roles of Moringa oleifera in rescuing $\mathrm{H}_{2} \mathrm{O}_{2}$ mediated changes in BMSC cell viability, cell cycle progression, oxidative stress, and expression of osteogenic markers. Moringa oleifera leaf exacts-containing serum significantly increased the expression of osteogenic differentiation associated genes, increased ALP activity and calcium deposition, maintained cell viability and proliferation, and relieved oxidative stress caused by $\mathrm{H}_{2} \mathrm{O}_{2}$ in BMSCs. Further mechanistic studies suggested that the protective roles of Moringa oleifera in damaged BMSCs were associated with the activation of the PI3K/Akt signaling pathway and reduced apoptosis.

ROS can activate caspase-3, which in turn triggers the caspase cascade leading to apoptosis [33]. In this study, cell viability and proliferation of $\mathrm{H}_{2} \mathrm{O}_{2}$-treated BMSCs decreased significantly at $48 \mathrm{~h}$ after treatments, while intracellular ROS and MDA levels increased significantly, and SOD and GSH-PX activity decreased. Consistently, levels of cleaved caspase-3, a marker of apoptosis, increased significantly in the $\mathrm{H}_{2} \mathrm{O}_{2}$-treated BMSCs starting at $24 \mathrm{~h}$ after treatments. These results indicate that $\mathrm{H}_{2} \mathrm{O}_{2}$ can significantly reduce cell viability and proliferation by activating intracellular oxidative stress and apoptosis. In addition, in vitro peroxidative damage has also been reported to exert a negative effect on osteogenic differentiation [34, 35]. We found that $\mathrm{H}_{2} \mathrm{O}_{2}$ not only decreased cell viability and the cell proliferation index in BMSCs, but also significantly reduced expression of osteogenic differentiation-associated genes, including ALP, collagen I, OPN, and Runx2. Moringa oleifera leaf extracts-containing serum partially reversed the $\mathrm{H}_{2} \mathrm{O}_{2}$-induced changes, and this effect was blocked by wortmannin. Moreover, the therapeutic effects of Moringa oleifera in enhancing BMSC osteogenic differentiation were further confirmed by ALP and alizarin red staining, an important marker of cellular calcium deposition [36]. However, Moringa oleifera leaf extractscontaining serum did not change these indicators under normal culture conditions.

Our results suggest that Moringa oleifera leaf exactscontaining serum activates PI3K, which plays a role in promoting osteogenic differentiation of $\mathrm{H}_{2} \mathrm{O}_{2}$-damaged BMSCs. In mouse bone pre-osteoblast MC3T3-E1 cells, the PI3K/Akt signaling pathway was also shown to promote osteogenic differentiation [37]. Studies have shown that activation of Akt enhances the activity of the transcription factor MyoD in myoblasts, thus inducing differentiation into myocytes and incorporation into regenerative muscle fibers [38-40]. Here, we showed that the Akt pathway was activated during BMSC osteogenic induction. Moringa oleifera leaf extractscontaining serum further increased the ratio of pAkt/ Akt and promoted osteogenic induction. Akt activation was significantly decreased in $\mathrm{H}_{2} \mathrm{O}_{2}$ injured cells, while Moringa oleifera leaf exacts-containing serum prevented the decrease in the pAkt/Akt ratio caused by $\mathrm{H}_{2} \mathrm{O}_{2}$. It is worth noting that Moringa oleifera leaf exactscontaining serum also increased the ratio of pAkt/Akt in BMSCs without $\mathrm{H}_{2} \mathrm{O}_{2}$ challenge. The detailed mechanisms by which Moringa oleifera leaf exacts enhance PI3K/Akt signaling under stress and non-stress conditions need to be further investigated.

Foxol acts as an important regulator of antioxidant stress and oxygen free radical balance during bone formation. The PI3K/Akt/Foxo1 pathway has been reported to play an important role in bones and muscles [41-44]. However, recent studies have shown that the role of Foxo1 in osteogenic differentiation is controversial. It has been reported that Foxo1 expression was increased after inhibition of PI3K [44], while another study reported that FOXO deletion in Osx1-Cre-expressing cells increased bone formation by activating Wnt signaling [45]. Most studies suggest that Foxo1 can improve osteogenic differentiation of osteoblasts. For example, Foxo1 gene knockout mice have reduced bone density and reduced osteogenic differentiation [46]. It has been reported that suppressing Foxo1 expression inhibits 
osteoblast proliferation, inhibits bone formation, reduces bone density, and increases oxidative stress levels [47]. Furthermore, it been shown that TNF- $\alpha$ inhibits Foxo1 by up-regulating miR-705, aggravating oxidative damage in BMSCs during osteoporosis [48]. In this study, we confirmed that oxidative damage by $\mathrm{H}_{2} \mathrm{O}_{2}$ decreased Foxo1, which was reversed by Moringa oleifera leaf extracts-containing serum. Therefore, our study suggests that Foxo1 has an important role in attenuating oxidative damage in BMSCs undergoing osteogenic differentiation. Under normal culture conditions, Moringa oleifera leaf extracts-containing serum did not change Foxo1 expression in BMSCs. In contrast, Foxo1 expression showed a trend consistent with that of Akt phosphorylation in response to $\mathrm{H}_{2} \mathrm{O}_{2}$ stimulation, and this trend was reversed by wortmannin. These results indicate that PI3K/Akt/ Foxo1 signaling in BMSC osteogenic differentiation might be augmented in response to peroxidative damage.

This study has some limitations. First, the Moringa oleifera leaf contained a variety of active ingredients [49]. In this study, we only performed non-target analysis of drug-containing serum, which was based on a preliminary experiment. Although we did demonstrate that the drug-containing serum was effective, further analyses of specific active ingredients in the serum with assays like a physicochemical analysis will require additional substantial work, and we believe this can help understand the more in-depth cellular and molecular mechanisms of the Moringa oleifera leaf in antioxidation and modulating osteogenic differentiation of BMSCs. Second, in the present study, rat BMSCs were isolated and confirmed with a typical morphology. They were positive for CD44 and CD90 and were negative for CD31 and CD34. However, we did not have a cell line with a known surface marker expression pattern as a positive control to authenticate MSCs. Third, we used rat serum and fetal bovine serum in our experiments, and found no statistical difference in the tested indicators between these two serum treatments (data not shown). For ethical considerations, rat serum was used for the experiments involving drug-containing serum, while the remaining experiments were performed with culture medium supplemented with fetal bovine serum.

In summary, our results show that $\mathrm{H}_{2} \mathrm{O}_{2}$ can negatively regulate osteogenic induction of rat BMSCs through inhibiting cell proliferation, reducing cell viability, causing oxidative damage, and inactivating the PI3K/Akt/Foxo1 pathway. Moringa oleifera leaf extracts-containing serum positively regulated BMSC osteogenic differentiation through restoring cell proliferation and viability, reducing peroxidative damage, inhibiting apoptosis, and activating the PI3K/Akt/Foxo1 pathway. Our work supports the clinical use of Moringa oleifera leaf extracts to treat patients with osteoporosis due to aging and peroxidative damage, and also suggests that administration of Moringa oleifera leaf extracts could be a promising strategy to prevent osteoporosis and reduce frailty.

\section{Abbreviations}

AKT: Protein kinase B; BMSC: Bone marrow mesenchymal stem cell; DMEM: Dulbecco's modified Eagle's medium; FoxO1: Forkhead Box 01; GSHPX: Glutathione peroxidase; H2O2: Hydrogen peroxide; MDA: Malondialdehyde; MTT: 3-(4,5-dimethylthiazol-2-yl)-2,5-diphenyl-2-Htetrazolium bromide; OS: Third passage of BMSCs was cultured in osteogenic differentiation medium; MO: Third passage of BMSCs was cultured in osteogenic differentiation medium supplemented with 10\% Moringa leaf extract-containing serum; P3: Third passage of BMSCs;

PI3K: Phosphatidylinositol 3-kinase; ROS: Reactive oxygen species; SEM: Standard error of the mean; SOD: Superoxide dismutase; TBST: Trisbuffered saline Tween 20; Wor: Wortmannin

\section{Acknowledgements}

Not applicable.

\section{Authors' contributions}

$M L, X W$, and $G L$ conceived and designed the project. $M L, H F$, and $M F$ acquired the data. $M L, L Y, H Z$, and $X L$ analyzed and interpreted the data. $M L$ wrote the paper. All authors read and approved the final manuscript.

\section{Funding}

This study was supported by a grant from Heilongjiang Provincial scholarship programs (Grant No. QC2009C34).

Availability of data and materials

The analyzed datasets generated during the study are available from the corresponding author on reasonable request.

\section{Ethics approval and consent to participate}

This study was approved by the Institutional Animal Care and Use Committee of Harbin Medical University.

Consent for publication

Not applicable.

\section{Competing interests}

The authors declare that they have no competing interests.

Received: 28 August 2020 Accepted: 8 February 2021

Published online: 20 February 2021

\section{References}

1. Sugiyama D, Kang S, Arpey N, et al. Hydrogen peroxide induces muscle nociception via transient receptor potential ankyrin 1 receptors. Anesthesiology. 2017;127:695-708.

2. Tom SE, Adachi JD, Anderson FA Jr, et al. Frailty and fracture, disability, and falls: a multiple country study from the global longitudinal study of osteoporosis in women. Journal of the American Geriatrics Society. 2013;61: 327-34.

3. Cesari M, Calvani R, Marzetti E. Frailty in Older Persons. Clin Geriatr Med. 2017:33:293-303.

4. Hendrickx G, Boudin E, Van Hul W. A look behind the scenes: the risk and pathogenesis of primary osteoporosis. Nature Reviews Rheumatology. 2015; 11:462.

5. Dennison EM, Harvey NC, Cooper C. Programming of osteoporosis and impact on osteoporosis risk. Clinical obstetrics and gynecology. 2013;56:549.

6. Miller PD. Management of severe osteoporosis. Expert Opin Pharmacother. 2016:17:473-88.

7. Watts NB. Insights from the Global Longitudinal Study of Osteoporosis in Women (GLOW). Nat Rev Endocrinol. 2014;10:412-22.

8. Dominici M, Le Blanc K, Mueller I, et al. Minimal criteria for defining multipotent mesenchymal stromal cells. The International Society for Cellular Therapy position statement. Cytotherapy. 2006:8:315-7.

9. Orbay H, Tobita M, Mizuno H. Mesenchymal stem cells isolated from adipose and other tissues: basic biological properties and clinical applications. Stem Cells Int. 2012;2012:549-57. 
10. Williams AR, Hare JM. Mesenchymal stem cells: biology, pathophysiology, translational findings, and therapeutic implications for cardiac disease. Circulation research. 2011;109:923-40.

11. Ren $G$, Chen $X$, Dong F, et al. Concise review: mesenchymal stem cells and translational medicine: emerging issues. Stem cells translational medicine. 2012;1:51-8.

12. Meng J, Ma X, Wang N, et al. Activation of GLP-1 receptor promotes bone marrow stromal cell osteogenic differentiation through $\beta$-catenin. Stem cell reports. 2016;6:579-91.

13. Kim K-I, Park S, Im G-I. Osteogenic differentiation and angiogenesis with cocultured adipose-derived stromal cells and bone marrow stromal cells. Biomaterials. 2014;35:4792-804.

14. Phetfong J, Sanvoranart T, Nartprayut $K$, et al. Osteoporosis: the current status of mesenchymal stem cell-based therapy. Cell Mol Biol Lett. 2016;21: 12.

15. Ocarino Nde M, Boeloni JN, Jorgetti $V$, et al. Intra-bone marrow injection of mesenchymal stem cells improves the femur bone mass of osteoporotic female rats. Connect Tissue Res. 2010;51:426-33.

16. Wang Z, Goh J, Das De S, et al. Efficacy of bone marrow-derived stem cells in strengthening osteoporotic bone in a rabbit model. Tissue Eng. 2006;12: 1753-61.

17. Cao L, Liu G, Gan Y, et al. The use of autologous enriched bone marrow MSCs to enhance osteoporotic bone defect repair in long-term estrogen deficient goats. Biomaterials. 2012;33:5076-84.

18. Mbikay M. Therapeutic Potential of Moringa oleifera Leaves in Chronic Hyperglycemia and Dyslipidemia: A Review. Front Pharmacol. 2012;3:24.

19. Olurishe $\mathrm{C}$, Kwanashie $\mathrm{H}$, Zezi A, et al. Chronic administration of ethanol leaf extract of Moringa oleifera Lam.(Moringaceae) may compromise glycaemic efficacy of Sitagliptin with no significant effect in retinopathy in a diabetic rat model. Journal of ethnopharmacology. 2016;194:895-903.

20. Omodanisi E, Aboua Y, Oguntibeju O. Assessment of the antihyperglycaemic, anti-inflammatory and antioxidant activities of the methanol extract of Moringa oleifera in diabetes-induced nephrotoxic male wistar rats. Molecules. 2017;22:439.

21. Joung H, Kim B, Park H, et al. Fermented Moringa oleifera decreases hepatic adiposity and ameliorates glucose intolerance in high-fat diet-induced obese mice. Journal of medicinal food. 2017;20:439-47.

22. Jung IL, Lee JH, Kang SC. A potential oral anticancer drug candidate, Moringa oleifera leaf extract, induces the apoptosis of human hepatocellular carcinoma cells. Oncology letters. 2015;10:1597-604.

23. Panda S. Butanolic fraction of Moringa oleifera Lam. (Moringaceae) attenuates isoprotrenol-induced cardiac necrosis and oxidative stress in rats: an EPR study. EXCLI J. 2015;14:64.

24. Al-Asmari AK, Albalawi SM, Athar MT, et al. Moringa oleifera as an anticancer agent against breast and colorectal cancer cell lines. PloS one. 2015; 10:e0135814.

25. Fakurazi S, Sharifudin SA, Arulselvan P. Moringa oleifera hydroethanolic extracts effectively alleviate acetaminophen-induced hepatotoxicity in experimental rats through their antioxidant nature. Molecules. 2012;17(7): 8334-50.

26. Vergara-Jimenez $M$, Almatrafi M, Fernandez $M$. Bioactive components in Moringa Oleifera leaves protect against chronic disease. Antioxidants. 2017; 6:91.

27. Kushwaha S, Chawla P, Kochhar A. Effect of supplementation of drumstick (Moringa oleifera) and amaranth (Amaranthus tricolor) leaves powder on antioxidant profile and oxidative status among postmenopausal women. J Food Sci Technol. 2014;51:3464-9.

28. Fang Y, Chu L, Li L, et al. Tetramethylpyrazine protects bone marrowderived mesenchymal stem cells against hydrogen peroxide-induced apoptosis through PI3K/Akt and ERK1/2 pathways. Biol Pharmaceutical Bull. 2017:40(12):2146-52

29. Chiu L-H, Lai W-F T, Chang S-F, et al. The effect of type II collagen on MSC osteogenic differentiation and bone defect repair. Biomaterials. 2014;35: 2680-91.

30. Xie Z, Ye G, Wang P, et al. Interleukin-6/interleukin-6 receptor complex promotes osteogenic differentiation of bone marrow-derived mesenchymal stem cells. Stem Cell Res Ther. 2018;9:13.

31. Chen J, Crawford R, Chen C, et al. The key regulatory roles of the PI3KVAkt signaling pathway in the functionalities of mesenchymal stem cells and applications in tissue regeneration. Tissue Eng Part B Rev. 2013;19:516-28.
32. Manolagas SC. From estrogen-centric to aging and oxidative stress: a revised perspective of the pathogenesis of osteoporosis. Endocrine reviews. 2010;31:266-300.

33. Circu ML, Aw TY. Reactive oxygen species, cellular redox systems, and apoptosis. Free Radic Biol Med. 2010;48:749-62.

34. Melough $M$, Sun $X$, Chun O. The role of AOPP in age-related bone loss and the potential benefits of berry anthocyanins. Nutrients. 2017;9:789.

35. Gómez-Puerto M, Verhagen L, Braat A, et al. Activation of autophagy by FOXO3 regulates redox homeostasis during osteogenic differentiation. Autophagy. 2016;12:1804-16.

36. Wang C, Liu D, Zhang C, et al. Defect-related luminescent hydroxyapatiteenhanced osteogenic differentiation of bone mesenchymal stem cells via an ATP-induced CAMP/PKA pathway. ACS applied materials \& interfaces. 2016:8:11262-71.

37. Fujita T, Azuma Y, Fukuyama R, et al. Runx2 induces osteoblast and chondrocyte differentiation and enhances their migration by coupling with PI3K-Akt signaling. J Cell Biol. 2004;166:85-95.

38. Fujio Y, Guo K, Mano T, et al. Cell cycle withdrawal promotes myogenic induction of Akt, a positive modulator of myocyte survival. Molecular and cellular biology. 1999;19:5073-82

39. Wilson EM, Rotwein P. Control of MyoD function during initiation of muscle differentiation by an autocrine signaling pathway activated by insulin-like growth factor-II. Journal of Biological Chemistry. 2006;281:29962-71.

40. Sun L, Liu L, Yang $X-J$, et al. Akt binds prohibitin 2 and relieves its repression of MyoD and muscle differentiation. J Cell Sci. 2004;117:3021-9.

41. An Y-M, Li Y-J, Zhang C-L, et al. Decreased PKG transcription mediated by $\mathrm{PI3K} / \mathrm{Akt} / \mathrm{FoxO} 1$ pathway is involved in the development of nitroglycerin tolerance. Biochemical and biophysical research communications. 2019;508: 1195-201.

42. Margolis LM, Berryman CE, Murphy NE, et al. PI 3K-AKT-FOXO 1 pathway targeted by skeletal muscle micro RNA to suppress proteolytic gene expression in response to carbohydrate intake during aerobic exercise. Physiol Rep. 2018;6:e13931.

43. Sun M, Shinoda Y, Fukunaga K. KY-226 protects blood-brain barrier function through the Akt/FoxO1 signaling pathway in brain ischemia. Neuroscience. 2019;399:89-102.

44. Bartell SM, Kim H-N, Ambrogini $\mathrm{E}$, et al. FoxO proteins restrain osteoclastogenesis and bone resorption by attenuating $\mathrm{H} 2 \mathrm{O} 2$ accumulation. Nat Commun. 2014;5:3773.

45. lyer S, Ambrogini E, Bartell SM, et al. FOXOs attenuate bone formation by suppressing Wnt signaling. The Journal of clinical investigation. 2013;123: 3409-19.

46. Ambrogini E, Almeida M, Martin-Millan M, et al. FoxO-mediated defense against oxidative stress in osteoblasts is indispensable for skeletal homeostasis in mice. Cell metabolism. 2010;11:136-46.

47. Rached M-T, Kode $\mathrm{A}, \mathrm{Xu} \mathrm{L}$, et al. FoxO1 is a positive regulator of bone formation by favoring protein synthesis and resistance to oxidative stress in osteoblasts. Cell metabolism. 2010;11:147-60.

48. Liao L, Su X, Yang X, et al. TNF-a inhibits FoxO1 by upregulating miR-705 to aggravate oxidative damage in bone marrow-derived mesenchymal stem cells during osteoporosis. Stem cells. 2016;34:1054-67.

49. Teixeira EMB, Carvalho MRB, Neves VA, et al. Chemical characteristics and fractionation of proteins from Moringa oleifera Lam. leaves. Food Chem. 2014:47:51-4.

\section{Publisher's Note}

Springer Nature remains neutral with regard to jurisdictional claims in published maps and institutional affiliations. 